\title{
Investigar en videojuegos. Desde la creación al análisis, una visión panorámica de un medio en crecimiento
}

\author{
Dr. Emilio Sáez Soro \\ Director del Grado en Comunicación Audiovisual \\ Universitat Jaume I \\ Dr. Miguel Chover Sellés \\ Director del Grado en Diseño y Desarrollo de Videojuegos \\ Universitat Jaume I
}

El crecimiento del mercado de los videojuegos no solo ha repercutido en el crecimiento del número de empresas, productos y en el dinero ingresado sino que se han convertido en los últimos años en un producto mediático y de gran riqueza de matices en su construcción. De la misma forma, por su naturaleza interactiva y por la introducción de la comunicación como base para un juego colectivo y virtual se ha integrado mucho más en la diversidad social.

Este crecimiento ha producido su entrada en el escenario mediático pisando con fuerza y reivindicando el reconocimiento de la relevancia que les da un público muy numeroso que crece año a año. Dicho crecimiento se produce de forma simultánea en una tipología de temáticas y formas de jugabilidad creciente que atraen a un mayor número de personas. Esta dinámica empuja a los diseñadores a seguir explorando nuevos públicos concibiendo formatos innovadores.

Esta mayor variedad y complejidad de los videojuegos ha supuesto una progresiva incorporación de recursos de otros productos culturales como la literatura, el cine, la fotografía, la televisión y en general cualquier manifestación artística. La plasticidad y porosidad de este medio permite integrar en su lógica cualquier otro contenido dada su capacidad omnímoda de replicar en lo digital e interactivo toda manifestación humana.

Esta situación supone a los creadores un reto y una oportunidad porque se plantea la posibilidad de acercarse más al público gracias a la interactividad obligatoria. Pero la creación y la lectura de los videojuegos han de realizarse en la lógica que supone su introducción en el código de la acción del jugador 
sobre los mismos. Por ello, en la creación y análisis sobre los conocimientos convencionales de dichos contenidos se precisa de una mirada que los integre en esa relación diferente con el usuario-espectador-jugador y que la ubique en escenarios virtuales. El punto de observación prioritario es la centralidad de la interacción y la comunicación como factores que aportan la energía a estos productos en los que todos los demás contenidos cobran vida.

En este número de adComunica se presta una especial atención al mundo de los videojuegos desde la perspectiva amplia de la comunicación, en la que estos son muy interesantes tanto en su proceso de creación y producción, como en lo referente a su relación con otros entornos mediáticos como es el publicitario. Contribuimos así al esfuerzo de otras revistas de este ámbito que vienen prestando una atención importante desde hace años a esta temática, objeto del trabajo continuo de investigadores de este campo científico. Sin embargo esta mirada no sería posible sin considerar el aspecto multidisciplinar que supone la creación de los videojuegos. No se pueden comprender sin el fundamental componente informático, artístico en todas sus dimensiones, psicológico y sociológico, así como toda la dimensión económica que influye de forma notable en la evolución de las producciones. Y un rasgo común de todas estas áreas de conocimiento es que en ningún caso trabajan disociadas porque solo con una excelente integración de todos esos círculos del saber pueden resultar juegos interesantes. Así, el diseño de videojuegos es hoy una de las disciplinas más transversales en la medida que supone la necesaria integración de cada vez más elementos en busca de la jugabilidad óptima.

El tratamiento en la creación e incorporación de contenidos audiovisuales al diseño y desarrollo de videojuegos está sujeto a esa lógica. Crear para ellos o adaptar, en el sentido de que un contenido en este marco es utilitario para el jugador y en esa forma tiene que servir para que funcione. Así la investigación sobre el videojuego como objeto mediático ha de consistir en una mirada integradora en la que el resultado se canalice como juego, buen o mal juego y en qué medida todos los demás elementos contribuyen a ese estado.

De esta manera la misma imagen que puede funcionar a la perfección como representación en un contexto cinematográfico, televisivo o impreso puede ser problemática en un escenario virtual interactivo en la que el punto de vista lo va a determinar el jugador incluso contra nuestras pretensiones. Aspectos como la iluminación cobran una importancia fundamental para generar mecanismos narrativos que a su vez marcan los pasos del jugador en la acción. El artículo de Marta Fernández Díaz Claves creativas de la iluminación en los videojuegos. Una propuesta metodológica para el entendimiento de la luz en los entornos tridimensionales lúdicos supone un interesante e innovador trabajo para clarificar el papel de la iluminación vinculado a la narrativa del videojuego. Del mismo modo un guión mal establecido puede ser obviado por los jugadores pasando a elementos de jugabilidad que no dependan del mismo por lo que perdería completamente su sentido, algo que ha sucedido en numerosos casos. 
El artículo que presenta Víctor Navarro Remesal ¿La vida empieza o acaba con el matrimonio?: amor, diseño de ética y libertad dirigida en Catherine constituye un buen ejemplo de como una historia se integra en el juego aportándole sentido, emoción, facilitando su continuidad.

Del mismo modo podemos valorar aspectos novedosos en los productos mediáticos como la introducción de canales de comunicación que de forma especial en los videojuegos han supuesto la creación de poderosas plataformas sociales de juego. Establecer el diseño de unos mecanismos idóneos para una comunicación eficaz y estimulante que fortalezca y mantenga la dinámica de juego se convierte en una de las líneas de investigación más interesante. La comunicación en este aspecto cobra una gran relevancia cuando se vehiculan técnicas publicitarias, algo de lo que en este caso podemos tomar clara conciencia con la lectura del artículo de Seone, Sanjuan y Martínez, Visibilidad y recuerdo del product placement en videojuegos en los que el uso de objetos y sus implicaciones tienen utilidades con un gran potencial para el mundo publicitario.

En lógica comunicativa es fundamental para mantener un vínculo efectivo en la interactividad y jugabilidad que el videojuego esté bien traducido y contextualizado en la cultura que lo recibe. En este contexto el artículo de Ramón Méndez, La localización como factor clave en el proceso de desarrollo de un videojuego aporta un análisis en profundidad de la relevancia de estos procedimientos de adaptación del videojuego a su contexto social y cultural.

Para terminar, no podemos obviar la peculiar situación del mercado del videojuego en España, donde se consume mucho y se produce poco. El reto de la formación de un tejido productivo en nuestro país es uno de los aspectos más relevantes como horizonte en el que el trabajo de los investigadores ha de contribuir a apoyar este proceso. En este aspecto es de gran interés el trabajo de José Patricio Pérez Modelos de producción del videojuego en España con una mirada muy clarificadora sobre los procedimientos de creación y producción de videojuegos.

Agradecemos a sus autores este conjunto de aportaciones porque son una valiosa contribución en la investigación del ámbito de la comunicación pero con una perspectiva multidimensional como corresponde a un objeto como son los videojuegos.

\section{Referencia de este artículo}

Sáez Soro, Emilio y Chover Sellés, Miguel (2015). Investigar en videojuegos. Desde la creación al análisis, una visión panorámica de un medio en crecimiento. En: adComunica. Revista Científica de Estrategias, Tendencias e Innovación en Comunicación, $n^{\circ}$ 9. Castellón: Asociación para el Desarrollo de la Comunicación adComunica, Universidad Complutense de Madrid y Universitat Jaume I, 15-17. DOI: http://dx.doi.org/10.6035/2174-0992.2014.9.2. 